\title{
In search of social work's post-risk paradigm
}

\author{
Joe Smeeton ${ }^{1}$
}

\begin{abstract}
This paper describes a paradigmatic shift in child protection practice within the UK, arguing that there is a move away from the risk paradigm but that its replacement is not yet defined. The paper draws upon the critical literature to elucidate this shift and to give examples and arguments for why the risk paradigm is unsustainable and how this has created an essential tension within the profession. While the case against the risk perspective is strongly argued there is not yet a coherent perspective to replace it which is problematic as practitioners are left with a toolkit of technical interventions to guide their practice but what is missing is the capacity to develop an ethic of practice due to a failure of social work in the UK to engage with philosophical questions about its remit. The conclusion is drawn that social work needs to focus more on ethical fluency rather than being stuck on statistical understandings of practice and policy in order to achieve a shift in paradigm from 'risk' to 'ethics'.
\end{abstract}

Keywords: child protection; risk; philosophy; ethics; social work practice

1. Lecturer in Social Work, University of Sheffield

Address for correspondence: J.Smeeton@sheffield.ac.uk

Date of first (online) publication: 18th December 2019 
... being a man [sic] of good or sympathetic judgement consists in being able to judge about things with which practical wisdom is concerned; for what is equitable is the common concern of all good men in their dealings with others' (Aristotle, 2009, p.113)

\section{Introduction}

This discussion paper draws upon the child protection social work literature on risk at a time when the profession is on the cusp of a paradigmatic shift in the way it thinks about its remit and everyday business. It also, however, speculates on what will become the everyday tasks and concerns of child protection social workers in the post-risk paradigm. If we have, as this paper will argue, a profession that is saturated with risk thinking that permeates its everyday decision-making, we have to have some thought about what will replace that preoccupation with risk in the everyday small actions and interactions of child protection social workers who will still carry the burden of societal expectations to protect children from harm. It is also written at a point in time when referrals are extremely high, according to Bilson \& Martin (2017) 22.5 percent of children born in 2009-10 were referred to children's social care before their 5 th birthday.

In order to work towards an answer to the question as to what will fill that gap, this paper will incorporate critical literature on risk thinking that puts the current epistemology of child protection in a state of 'essential tension' that Kuhn (1996, pp. 78-79) describes as necessitating a paradigmatic shift. It will then go on to interrogate other forms of thinking about the fundamental role of child protection social work before settling on a discussion about ways forward by arguing that there is a need for increasing social workers ability to think about questions on the purpose of child protection social work and how that translates into everyday decision-making. The argument will be put that social work needs to develop its ethical literacy and practice in order to escape the risk paradigm and social work education needs to allow space for qualifying and post-qualifying students to develop that literacy.

\section{Literature discussion}

\section{The risk paradigm}

A paradigm is '... a mode of viewing the world which underlies the theories and methodology of ... a particular period of history' (Oxford English Dictionary, 2002) Kuhn uses the term to relate to high order understandings that incorporate a collection of ideas that operate within a period of time that could be said to be 
characterised by that paradigm. Paradigms serve to '...implicitly define the legitimate problems and methods of a research field for succeeding generations of practitioners' (Kuhn, 1996, p. 10). He argues that as such they share two essential characteristics: their achievement was sufficiently unprecedented to attract an enduring group of adherents away from competing modes; and they are sufficiently open-ended to leave all sorts of problems for the redefined group of practitioners to resolve. Under this definition of 'paradigm' I would argue that the practices and literature I draw on in this paper co-exist within social work's 'risk' paradigm, a collection of theories, methodologies and understandings which characterise social work practice over recent history.

There is a fundamental difference between thinking about risk to older autonomous adults who are viewed as, for the most part, having agency and work with children who are often conceptualised as lacking legal and cognitive agency. This paper will focus on local authority child protection social work in the UK for that is the area I believe to currently be the most unstable within the 'risk' paradigm. However, when we conflate children as one category of humanity, we are including neonates who are entirely dependent upon adults to survive in every way, with 17-year-olds who are adults in every sense other than legally. We therefore have to ask relevant moral questions in deciding social work's remit to its service users across childhood from complete dependence to autonomy. There is not one set of principles and values that can operate across such a wide spread of development and agency therefore social workers need to be able to develop and tailor moral decisions to the individual before them.

Webb (2006) is the primary source for translating Beck's $(1992,2007)$ thinking into the social work context, but where his focus is in dealing with social work in a 'risk society', this paper is attempting here to deal with risk within the profession. Webb (2006, p.4) seeks to show how the preoccupation with risk and the problems which arise within neo-liberal risk society are translated into social work and how, as a consequence, risk is produced, prevented, minimised, dramatised and channelled. Kemshall (2010) adopts a similar view that social work moved from a 'needs' paradigm to one concerned with risk but also argues that need and risk are conflated in assessing and determining service provision, through actuarial governance.

Parton (2011) similarly argues that policy and practice in relation to 'risk' have shifted considerably over the last forty years. He characterises child protection systems in the early 1990's as focusing on the identification of 'high risk' cases in order to protect children from abuse while not imposing the state into private family lives where it could avoid it. There arose the notion of 'dangerous families' who due to their extreme behaviours could be constructed as the primary cause of child abuse and were thus legitimate targets for state intervention. The state therefore sees its role as only protecting children from abuse rather than claiming a role in promoting children's developmental growth and ensuring their needs are met. 
From the mid 90's onwards the shift was towards supporting families to care for children through notions of partnership rather than coercive intervention. The titles of policy documents reflected this move from 'Protecting Children' to 'Working Together' and we started speaking about 'safeguarding children' rather than 'child protection'. Professional attention became drawn towards the risk of impairment to the child's overall development in the context of their family and community and away from the risk of 'significant harm' arising from abuse. Parton highlights this shift away from a focus on 'dangerousness' to one on 'risk'. Children who were in danger became a subset of children who were in need. All of this underpinned by The Children Act - 1989 concern to assess and intervene in situations where children were thought to be 'suffering, or likely to suffer, significant harm.' Parton (2011) argues that it also shifted the focus to intervention at a much earlier stage in order to prevent a range of problems in childhood and later life including poor educational attainment, unemployment and criminal behaviour, rather than responding posthoc to incidents of abuse. What emerged then was a tiered model of need (Every Child Matters, 2004) with services tailored to intervention based upon the level of perceived vulnerability and risk to the child. France and Utting (2005; cited in Parton 2011) characterised this as the 'paradigm of risk and protection-focused prevention.' The claims of predictive powers that arise from a belief that certain characteristics (risk factors) increase the likelihood that children will experience negative outcomes forms the basis for state intervention. The more risk factors that are present the more likely it is that the child will have negative outcomes. Parton highlights a dramatic swing back to 'Child Protection' following the death of Peter Connolly (Baby P) in 2008. The political and media attention that followed roused public outrage to start asking the questions about how this could happen, particularly as this family was receiving high levels of social work intervention in order to promote good outcomes for Peter. What they didn't know about were the very dangerous men living in the household and subjecting Peter to regular and severe violence. Here is a significant flaw in the belief that if we know all the factors, we can calculate the risk. We rarely know all the factors and families are more likely to hide the most concerning aspects because of their belief in how the social worker will respond to them.

The impact of this one case on decision making for families has been immense with year on year increases in care applications and ongoing difficulties with recruitment and retention of social work staff who saw their profession publicly castigated through high profile sackings. Garrett (2009; cited in Parton 2011) says the 'rancourous' social and media reaction to the death of Peter Connolly engendered a sense of high anxiety amongst government officials, children's services managers and practitioners. Interestingly the subsequent report by Laming (2009) started again to use the language of child protection rather than safeguarding and social work has since been expected to focus on the sharp end, leaving early intervention to other services.

Parton (2011) believes that the policy shifts that occurred under New Labour, 
well intentioned though they were, acted in the opposite direction by massively increasing the number of families who fell under the glare of the state's eye and thereby reduced the amount of time available to undertake effective interventions; by over-proceduralising the bureaucracy involved; and by broadening the focus on 'risk' conflating concerns about children and young people who might be 'at risk' from a whole variety of threats, including abuse, with other concerns about children and young people who might pose a threat to others through crime or anti-social behaviour. Parton argues that the defensiveness, risk avoidance and blame culture of the 90's permeated the new practice culture and was heightened by the highly anxious context post Peter Connolly that prioritised 'strict safety' and a logic of precaution'. The language of risk was stripped of its association with calculating possibilities and used in terms of preventing future harm and avoiding the 'worst case scenario'. I have characterised this shift as creating or at least cultivating the mood of anxiety that pervades the profession (Smeeton, 2018).

Webb (2006) describes two basic dimensions to risk that relate to social work within risk society; the logic of regulation and the logic of scrutiny. He argues that these logics are both systems responses to modern contingency and complexity. By regulating, organisations and the state govern and control a set of phenomena through a set of rule-bound procedures. Order, standards, conduct, calculation and rule adherence are its key concerns and it seeks to regulate against risk by setting targets and standardising rules in the belief that if the same patterns of behaviour are followed then there will be a predictable set of outcomes. Within social work this has led to a number of highly problematic working assumptions by organisations that Munro (2011, p.6) challenges in her assertion that social work has become too focused upon 'doing things right' (following procedures) rather than 'doing the right thing' (i.e. checking whether children and their families are being helped).

Webb's (2006) logic of regulation and scrutiny, mirror Weber's distinction between instrumental rationality, which is means driven, calculating, controlling and predicting; and substantive rationality, which focuses upon broad expressive values, affects and meanings. According to Heidegger (1977, cited in Webb, 2006, p.40) calculative thinking is the intellectual corollary of this instrumental rationality that through technology forms the modern world picture. Substantive rationality is governed by the idea that a certain form of behaviour is of absolute value in itself regardless of consequences, which according to Habermas (1990, cited in Webb, 2006, p.40) is a form of moral practical rationality where action is oriented to reaching an understanding. Webb (2006, p.13) problematises calculative reasoning (attempts to predict, estimate or count up definite results that are routinised in the social world) by drawing upon Heidegger, Nietzsche and Weber's critique of the modern age and the futility of relying on this way of thinking. Webb cites Heidegger as distinguishing between calculative and essential thinking to show how modern society's world view becomes dominated by calculation and therefore loses the creative vitality that life offers. 
Increasingly expert interventions are less concerned with fathoming the great riddles of unconscious life than with a modest sense of problem solving in the face of risk.... If individuals are unable to accept their responsibility for self-governance, then experts are required to do it for them. Social Work therefore becomes a safety net which buffers the vulnerable from uncertainties, crises and insecurities. (Webb 2006, p.37-38)

Social Work as an expert welfare system is one response to society's need to develop a rationality of security that both limits and enables members of that society (Webb 2006). The idea that social work is primarily an enabling profession is naive as there are important tasks given to it by society to control undesirable behaviours and to limit harm to vulnerable individuals within it. We therefore support the machinery and preoccupations of risk society through our role as experts in creating, identifying and managing risks. Society has delegated the job of managing uncertainty in the complex world of child protection to the social work profession and is therefore angry if it perceives that role isn't properly undertaken and expects trust and accountability. We are trapped within this logic of security that is dependent upon fragile trust that is broken with every child death that becomes a newspaper headline.

\section{Risk decision-making}

There are lots of critical voices in the social work literature for we realise that risk prediction is plagued with false positives (Milner and Myers, 2007). When we work from trying to understand people's lives from a risk perspective, we tend to err on the side of risk aversion which leads to bringing children into care who may not need to be there. 'In child protection, with its limited knowledge base, discriminating between avoidable and unavoidable errors is problematic' (Munro, 2010 p. 1146) so the rationale for decision-making is problematic. Keddell \& Hyslop (2019) point out the inherent risk-bias that arises as a product of ethnicity for example. Kemshall (2010) questions the existence of the rational actor 'Decisions are made but they are negotiated, collective and contingent on contextually based rationalities and perceptions of risk' (p. 1249)

So, who makes decisions and how are they made without a rational actor? Processes take over and are often contextualised within the supervision or case management procedure, where the actual decision to act is shared or shifted between the worker, the manager and the multi-disciplinary meeting. 'Individualised risk assessment has become a managerial device to both avoid and apportion blame' (Denney, 2005). Managers are thereby, proceduralised by their agency to engage themselves and workers in single-loop learning (Munro, 2010) where what is often required is double-loop learning that helps to adapt the original assumptions about risk. They are locked into what Webb (2006, cited in Kemshall, 2010) describes as 
'technologies of care, formalising decisions and creating audit trails of risk.'

Is this necessarily a bad thing if children are protected as many of them undoubtedly are? There is certainly some argument that the knowledge base and understanding behind the decision-making is questionable. Milner and Myers (2007) argue that constructing service users' identities as fixed restricts capacity for meaningful change; and that identities seen as 'essential' limit any notion of personal agency. We often see this in cases involving domestic violence where men are often seen as 'essentially' violent and incapable of change. The emphasis then is on encouraging the mother to leave the father in order to protect the child, disregarding any possibility that the person with the problematic behaviour is the one who needs to make the changes. However, affecting change in violent men is less certain and involves living with some ongoing likelihood that the child (and mother) may be harmed (that is, living with risk) so the pragmatic decision is taken to expect the mother to leave her partner. This chimes with Broadhurst et al's (2009) argument that a preoccupation with identifying, assessing and intervening on the basis of 'risk' serves to individualise social problems and to mask the structural, political and individual inequalities which often characterise the lives of vulnerable children and their families.

That systems and organisations revert inevitably to regulation in order to protect themselves from risk and to be accountable to society becomes highly problematic in several ways. I would argue that risk averse systems are primarily concerned with avoiding risk to themselves by ensuring that they can show that the organisation and individuals within it followed procedure. We find that there is often a belief that procedures in themselves will protect but if they don't then the decision-making is defensible regardless of the outcome. In the inquest relating to baby Alex Barker who died in 2007 while being prop-fed, the closure of the case was justified by the social work manager because, '... nobody had gone outside protocol', (The Star, 24.9.10). But the child died. Perhaps this was a completely unpredictable death that could not have been avoided by any protocol but perhaps on this occasion someone needed to go outside of protocol. A risk averse system restricts professional agency.

Munro (2010) similarly argues that the risk averse nature of organisations has created systemic approaches to risk that actually make it harder for social workers to protect children and argues for a conceptualisation of child protection services as complex adaptive systems. She argues that new public management approaches expect practitioners to comply with procedures and to have a belief that these procedures will protect, then fail to understand child deaths that occur when procedures are followed. Munro argues that the complex system of child protection should be able to adapt to understand complex and unique situations, but the strait jacket of compliance removes the practitioner's ability to do so without breaking rules. In breaking these rules social workers are taking professional risks that create anxiety and lead ultimately to recruitment and retention problems.

However, as Munro (2010) points out, the blame culture that arises from the risk 
society leads to practice that is masked by the procedural organisational responses. She uses Rothstein et al's (2006) distinction between societal risk (the risk to children of maltreatment) and institutional risk (the risk to professionals and agencies of being criticised) to illuminate the tendency of agencies to blame individuals for errors that lead to child deaths rather than learn from the case. We can therefore see how increased proceduralisation seeks to shift the focus away from the safety of the child to the safety of the organisation. Therefore, the defence of 'due diligence' leads senior managers to want to demonstrate how staff followed correct procedures in order to avoid harm to the organisation or that the individual worker was to blame because they broke the rules and are therefore individually responsible. Learning from tragedies has a tendency to simply generate more and more rules in order to avoid what is often a rare and unique set of circumstances leading to a child death. Munro gives the example of the Laming report (2009) which followed an enquiry into the death of Victoria Climbié, asking social care agencies to stop judging whether a referral from other professionals merits an assessment and to create a rule that all referrals receive one. This massively increased workloads and reduced the amount of time available for workers to engage with families to help them change problematic parenting, while at the same time offering a defence to the worker of 'I was following procedures' and an organisation's ability to show due diligence and then blame the worker for making the wrong decision, while creating the conditions that increase the likelihood of fallacious decisions.

The defensive controlling style of management is an understandable reaction to the level of blame from society when children die. However, it is a response that inadvertently encourages people to place the protection of themselves and their agencies above the protection of children. (Munro, 2010, p.1149)

Parrott (2014) falls into the trap of thinking about risk and hazard as synonyms. I have previously argued that they are not, and that risk is the likelihood of a hazard causing harm (Smeeton, 2018). However, I agree with Parrott's assertion (2014, p.102) that as services become more and more targeted towards people with more severe problems decision making becomes more complex and therefore more ethically demanding.

\section{Risk reification}

The World Health Organization (Krug et al 2002; Jütte et al. 2015) in trying to synthesise international understandings of harm to children identify a number of 'risk factors' for child abuse and neglect within an ecological model. The imprecision in language is unhelpful - what do we mean by risk factors? Some of these factors are described as vulnerabilities, suggesting that should a hazard cause harm then that 
harm is likely to be more severe. Others seem to be situations, factors that are more likely to contain or generate hazards. Worryingly, caregiver and family characteristics suggest that where these innate, essential characteristics exist there are more hazards and those hazards are more likely to cause harm. Is the social work job then, simply to identify and quantify these 'risk factors' and to reduce or remove either the factors or the child? This is why we are creating a discourse around the 'toxic trio' of factors where families are struggling with 'substance misuse', 'mental health problems' and 'domestic violence'. (Featherstone et al, p. 2014;) The simple presence of the toxic trio can send a social worker reaching for a car seat and a court order quicker than any risk assessment tool could predict.

Stanford's (2011) novel study illustrates the idea of 'risk reification' by an analysis of practitioners talk and how risk was 'spoken into existence'. She develops some really useful insights into how practitioners develop risk-identities for themselves and their service users as either 'at risk' or 'a risk'. Service users can be 'at risk' if they are vulnerable or 'a risk' if they pose a threat of harm to others while social workers can be 'at risk' from their dangerous service users or negatively judged by others or 'a risk' to service users through ineffective practice leading to negative consequences for service users. Of course, many practitioners in Stanford's study could recognise that service user and practitioner could also on occasions hold both identities and the interplay between them could lead to challenging practice dilemmas about which identity should be responded to and how this might lead to defensive practice. It seems staggering that practitioners are so easily able to indulge in an atomistic reduction of the human condition to that of risk, which is ontologically unstable. It is interesting to hear Stanford's description of practitioners questioning the reality of risk they were working with in order to destabilise client and practitioner risk identities and find new ways forward. Workers who were able to consider the dilemmas presented by these risk identities are described as balancing who was at greater risk - themselves or their clients, while workers who sought to 'control and dismiss' their clients seemed unable to reconsider their positions. I suppose workers own risk-identities may become fixed over time and as they become entrenched in practice positions there is a danger that they may only ever see themselves as 'at risk' or 'a risk' to their service users.

Heidegger cautions against such reification:

For it is said that subject and consciousness must not be reified, must not be treated as a purely extant thing: this has been heard for a long time at every philosophical street-corner; but now even this is no longer heard. (Heidegger, 1988, p. 323)

Stanford (2011) describes the importance of the organisational context for determining social workers risk identities and especially feelings of being 'at risk' in feeling isolated and fearing the imposition of sanctions if acting against organisational policies and cultures. From her small but interesting qualitative study, she reaches a description of risk as a personal moral issue for her respondent social workers, 
operating as a personal construct through the enmeshment of risk with the clients and practitioners' identities and their personal (rather than organisational) resolution of risk-based moral dilemmas. She also describes social workers splitting off their own human responses of compassion and empathy to their service users in favour of a risk-defined professional identity that informs their decision-making. Risk as a 'personal moral issue' seems to me to be the crux of this discussion and to light the way into the post-risk paradigm that requires a new moral literacy.

\section{Action in the post-risk paradigm}

It seems that we have indeed encountered a series of tensions within the risk paradigm that have undermined it to such a degree that it can no longer persist. In Kuhn's terms, it has encountered too many 'epistemological counterinstances' (Kuhn, 1996, p.78) for them to constitute more than a minor irritant. We must therefore permit the emergence of a new and different analysis and that seems to be a welcome shift in the practice environments of local authority children's services away from deficit models of understanding families to more constructive strengthsbased approaches. Increasingly we are seeing: solution focused approaches, often wrapped up as Signs of Safety (Turnell \& Edwards, 1999); systemic practice, usually based on the Hackney family systems model (Goodman \& Trowler (2011); and restorative practice approaches, often using Family Group Conferencing (Morris and Burford, 2009) as its main tool. However, at the same time we continue to marvel at the persistent rise in care order applications and the subsequent rising numbers of children in care. We may have merely replaced one technology with another without changing the fundamental way of thinking about the 'why' of social work. Connolly's (2017) engaging and insightful book 'Beyond the risk paradigm in Child Protection' offers an extensive critique about risk saturated practice, but it is surprising how easily contributors fall into an acceptance of the need to manage risk and indeed to incorporate new technologies of risk thinking such as those presented by neuroscience and strengths based interventions. Indeed, Morris \& Burford (2017, p. 104) argue that risk technologies should mesh with relational family-minded practice for a '...recalibration of the risk culture (which) might then better serve children, families and child protection systems.' This seems to be aimed at focusing practice on the cusp of the paradigm shift without fully moving beyond it. While we celebrate a move towards strengths-based approaches that have stronger roots in hopeful partnerships with families, there is a danger that we are simply replacing the risk of things going wrong with the risk of things going right and through binary thinking miss the complexity and richness of human experience that social work could enhance. Shlonsky \& Mildon (2017, p. 125) however, do offer hope of using assessment and decision-making in order to achieve '...nuanced understanding of individual outcomes for children and families with complex needs'. 
With the recent establishment of a nationally funded 'What Works Centre' in England, designed to elucidate and develop the evidence base, we may have a chance of trying to understand the effectiveness of practice interventions, but we seem to have not spent quite enough time thinking about the goals of child protection social work before asking how effective we are in reaching them. There is a danger through a 'what works' approach, that we boil social work effectiveness down to whether more or fewer children enter the care system. Should child protection social work not be about more than that? Should we not be aiming to improve the lives of children who may never have been likely to enter the care system? Should we not be improving the capacity and experience of parenting through poverty and an antagonistic climate to difference? Should the idea about 'family' be more than the relative success or failure to parent children? How do we begin to grasp the ontological structures with which social work concerns itself if we only focus upon a limited set of outcome indicators?

Webb (2006) worried that social workers tend to not have a comprehensive understanding of theory and are highly likely to adopt an eclectic 'what works' approach to practice, which he sees as an anti-intellectual stance closely tied to empiricism. He identifies 5 factors that explain the success of outcome based short term interventions ( $\mathrm{pl24)}$ :

- Short-term work is economically more resourceful and cost efficient whilst mirroring organisational changes in workplace culture

- Empiricism accrues legitimacy by its association with hard science

- Task and solution-focused models are not too intellectually demanding for practitioners

- The 'what works' syndrome is appealing because it makes sense

- Outcome-based models feed comfortably into the auditing and performance measurement culture

In arguing that adherence to a set of duty-bound rules or prescribed code of conduct is merely positioning practice as conformity, Webb (2006) posits that social work should have a commitment to an ethical life. He promotes Charles Taylor's existential phenomenological approach (Webb 2006, p. 203) as entailing an 'encounter with things that concern us' (Smith 2002, p.87), which mirrors my own argument for social work to be about Action in the Arendtian sense of the word (Smeeton, 2015).

So how do we decide what are the things that concern us? It seems that we have to know what paradigm will replace risk, for as Kuhn argues:

To reject one paradigm without simultaneously substituting another is to reject science itself. That act reflects not on the paradigm but on the man (sic). Inevitably he will be seen by his colleagues as 'the carpenter who blames his tools.' (Kuhn, 1996, p.79) 
We do seem to be rejecting the neo-liberal technical rationalization project that is firmly rooted in 'risk society'; we are increasingly rejecting deficit models for understanding families; we are sceptical to neuroscience and its allies in attachment theory; and we are sceptical of positivist empirical understandings. What then are the forms of questions that we need to begin to ask? Halvorsen (2018) argues that current social work teaching is rooted in normative ethics and lays the foundation for an argument that we ought to be developing social work students' ability to work with meta-ethical issues. In so doing we will require students to move beyond thinking 'what should I do?' onto thinking what are the possible right and wrong things, why are they right or wrong and what is the nature of that quality? In Benn's (1998, p.60) phrase 'Thus, we start theorizing about what is good and what makes an action right'. I would argue that in order to move students to this deeper level of thinking we also need to help them think through the ontological and epistemological concerns of social work: What is it to be human in a social world and how can we know it?

Featherstone et al (2014) set out the complexity of applying ethical frameworks in child protection processes and it is relatively easy to agree with their concurrence with Houston's (2010) argument for a discourse ethics that integrates deontology, consequentialism and ethics of care, but it is hard to see how this is easily transferred into the daily thinking of child protection social workers located in agencies fixed within 'Risk Society' (Beck 1992). It is harder to imagine unless we believe that social work education has equipped its graduates with the fluency of philosophical thinking and skills that are required. Yet this is often stuck in teaching Kantian ethics and professional codes of practice. In promoting Taylor's philosophy, (which is most celebrated in his discussion of the development of the self by drawing on both analytic and continental traditions) (Audi, 1999; Taylor, 1989), Webb (2006) argues that ethical practice should not be rule bound or based on codes of conduct as these rob the social worker of their own moral identity and replace it with the profession's or the agency's moral identity. He also recognises that 'reflective practice' as perpetuated in the social work literature has very little to say about ethics and that reflexivity is necessarily an ethical evaluation whereby the practitioner should confront themselves. What appears to be missing though is an ability to fully confront others in the profession through a facile relativist acceptance that everybody has his or her own 'values' which we ought not to challenge as these values are one's own concern and ought to be respected. Fisher and Freshwater (2015) assert that Taylor would reject a rationalist-instrumentalist mindset uncontaminated by emotion or value-judgment as an appropriate professional stance but would argue for an emotional attachment that extends beyond task-based competency or organisational compliance. The task therefore, that I will address in future work, is how to equip the workforce with the skills to deal ethically with specific issues within their work while weaving between individualism and instrumental reason. 
I believe that Taylor offers an interesting base by examining the self in a moral space (Taylor, 1989). My argument is that social workers need to move away from their 'risk identities' as described above by Stanford (2011), towards developing their moral, ethical identities. I have previously argued (Smeeton, 2015) that a reexamination of Aristotle's concept of phronesis, '... a quality of mind...that consists of being open to experience and prepared to take moral responsibility for actions and their consequences' (Stang, 2018, p.4) is required. This seems like fertile ground for future development.

\section{Conclusions}

I find it hard to maintain Webb's (2006) optimism in social work's commitment to an ethical core as the intervening years have seen it buckle under the strain of wave after wave of risk-saturated policy drives. Social Workers often find themselves at the fork of highly contested legal dispositions such as adoption with its dramatic effect on the legal status of birth parents (Herring, Probert \& Gilmore, 2015; Ward and Smeeton, 2017) and on a daily basis they are expected to make and apply ethical judgments but without space for, or skills in, philosophical reflection on the nature of moral judgment or metaethics (Benn, 1998). There is often a proud restatement of professional values rooted in understandings of structural oppression that help us claim the moral high ground, but we rarely review their relevance, content or application. According to Fisher and Freshwater (2015) Taylor would regard these dearly held values as important but transitory products that emerge through a neverending process of identity construction. We cannot therefore cling forever onto professional and personal values as though they are constant and eternal absolutes. What social workers need then is space and skill to 'strongly evaluate' their practice. Webb sees the development of ethical justifications as crucial if we are to argue for a sustained social work role in neo-liberal risk society. In doing so he is, to some degree, accepting that practice continues to take place within a risk paradigm. I would argue that we need to develop our ethical fluency in order to displace it. Social Work Education then needs to expand its remit further into helping students explore what it is to be human within society and to not be limited by the ontical concerns of sociology and psychology but to fully engage with the ontological and ethical concerns that philosophy can enable.

To fully understand social work theories, to be able to reduce ambiguities and to avoid misunderstandings, the practitioner must be able to identify the actual philosophical assumptions. Philosophical insight will also enable the social worker to address some complicated professional issues and to question ways of professional reasoning that should be challenged'. (Halvorsen, 2018:9) 
Social Work has always struggled with its own eclecticism. We are informed by macro theories of politics and social policy, meso theories of sociology and interactionism, and micro theories of psychology and biology. We bring professional values to these, but do we bring an ethic? There are certainly political, sociological and psychological questions that we regularly ask, but we seem to have stopped asking philosophical ones. We are of course concerned with the physicality of children and families and the impacts to their embodied existence of austerity, poverty and abuse without asking ourselves why? Maybe the potential answers to those questions are unpalatable, but it seems without social workers being clear about why they are doing their work then they are simply operating as technicians in the 'care' industry with 'care' having lost its meaning of human concern for others. These are philosophical questions, yet we spend very little time as a profession trying to understand what it is to be human from philosophical positions. Instead we have been entrapped by modernity into risk rationalities and intervention techniques informed by empiricism, which is important as it deals with the 'what' and 'how' of matter, but we need philosophy to ask, does it and should it matter?

And sympathetic judgment is judgment which discriminates what is equitable and does so correctly; and correct judgment is that which judges what is true. (Aristotle 2009, p.113)

\section{References}

Aristotle (2009) The Nichomachean Ethics. Oxford: Oxford University Press

Audi, R. ed (1999) The Cambridge Dictionary of Philosophy. Cambridge: Cambridge University Press.

Barnes, M. and Prior, D. (Eds) Subversive Citizens. Bristol: Policy Press

Beck, U. (1992) Risk Society: Towards a New Modernity. London: Sage

Beck, U. (2007) World at Risk. Cambridge: Polity Press

Benn, P. (1998) Ethics: Fundamentals of Philosophy. London: UCL Press

Bilson, A. and Martin, K.E.C. (2017) Referrals and child protection in England: one in five children referred to children's services and one in nineteen investigated before the age of five. In British Journal of Social Work 47, 793-811

Broadhurst, K. Grover, C. and Jamieson, J. (2009) Critical Perspectives on Safeguarding Children. Chichester: Wiley-Blackwell

Connolly, M (2017) Beyond the Risk Paradigm in Child Protection. London: Palgrave.

Denney, D. (2005) Risk \& Society. London: Sage

Featherstone, B., White, S. and Morris, K. (2014) Re-imagining Child Protection: Towards humane social work with families. Bristol: Policy Press 
Fisher, P. and Freshwater, D. (2015) An emancipatory approach to practice and qualitative inquiry in mental health: finding 'voice' in Charles Taylor's Ethics Of Identity. Ethics and Social Welfare, 9, 1, 2-17, DOI: 10.1080/17496535.2014.884611

France, A. and Utting, D. (2005) The paradigm of 'risk and protection-focussed prevention' and its impact on services for children and families. Children \& Society, 19, 2, 77-90.

Garrett P-M (2009) Transforming' Children's Services: Social work, neoliberalism and the 'modern' world. Maidenhead: Open University Press

Goodman, S. and Trowler, I. (Eds.) (2012) Social Work Reclaimed. London: Jessica Kingsley Gray, M and Webb, S.A. (eds) Ethics and Value Perspectives in Social Work. Basingstoke: Palgrave. Habermas, J. (1990) Moral Consciousness and Communicative Action. (Trans. C. Lenhardt and S.W. Nicholsen) Cambridge, MA: MIT Press

Halvorsen, T (2018): 'Philosophy of social work - a new and advantageous field of training and research'. Journal of Social Work Practice, DOI: 10.1080/02650533.2018.1438994

Heidegger, M (1977) The Question Concerning Technology and Other Essays. (Trans W. Lovitt) New York: Harper \& Row

Heidegger, M. (1988) The Basic Problems of Phenomenology. Bloomington: Indiana University Press

Herring, J., Probert, R. and Gilmore, S. (2015) Great Debates in Family Law. London: Palgrave Houston, S. (2010) Discourse Ethics. in M. Gray and S.A. Webb (Edss) Ethics and Value Perspectives in Social Work. Basingstoke: Palgrave.

Jütte, S., Bentley, H., Tallis, D., Mayes, J., Jetha, N., O’Hagan, O., Brookes, H. and McConnell, N. (2015) How Safe Are Our Children?: The most comprehensive overview of child protection in the UK. London: NSPCC

Keddell, E. and Hyslop, I. (2019) Ethnic inequalities in child welfare: The role of practitioner risk perceptions. Child \& Family Social Work. 24, 409-420 DOI: 10.1111/cfs.12620

Kemshall, H. (2010) Risk rationalities in contemporary social work policy and practice. British Journal of Social Work, 40, 1247-1262

Krug, E.G., Dahlberg, L.L., Mercy, J.A., Zwi, A.B. and Lorenzo, R. (2002) World Report on Violence and Health. Geneva: World Health Organisation

Kuhn, T.S. (1996) The Structure of Scientific Revolutions. (3rd ed.) Chicago: University of Chicago Press.

Laming, Lord (2009) The Protection of Children in England: A Progress Report. London: The Stationery Office.

Milner, J. and Myers, S. (2007) Working with Violence: Policies and practices in risk assessment and management. Basingstoke: Palgrave Macmillan

Morris, K. and Burford, G. (2009) Family Decision-Making: New spaces for resistance and participation. in M. Barnes and D. Prior (Eds.) Subversive Citizens. Bristol: Policy Press

Morris, K. and Burford, G. (2017) Engaging families and managing risk in practice. in M. Connolly (Ed.) Beyond the Risk Paradigm in Child Protection. London: Palgrave (pp. 91-108)

Munro, E. (2010) Learning to reduce risk in child protection.British Journal of Social Work. 40, 1135-1151

Munro, E. (2011) The Munro review of Child Protection. Final Report: A child-centred system. 
London: Department for Education

Oxford English Dictionaries (2002) Shorter Oxford English Dictionary, Oxford: Oxford University Press.

Parrott, L. (2014) Values and Ethics in Social Work Practice. London: Sage

Parton, N. (2011) Child protection and safeguarding in England: Changing and competing conceptions of risk and their implications for social work. British Journal of Social Work. 41, 854-875

Rothstein, H., Huber, M. and Gaskell, G. (2006) A theory of risk colonization: The spiralling regulatory logics of societal and institutional risk. Economy and Society, 35, 91-112. cited in Munro, E. (2010) Learning to reduce risk in child protection. British Journal of Social Work, 40, 1135-1151

Shlonsky, A and Mildon, R. (2017) Assessment and decision making to improve outcomes in child protection. in M. Connolly (Ed.) Beyond the Risk Paradigm in Child Protection. London: Palgrave (pp.111-129)

Smeeton, J. (2015) From Aristotle to Arendt: A phenomenological exploration of forms of knowledge and practice in the context of child protection social work in the UK. Qualitative Social Work 16, 1, 14-28 https://doi.org/10.1177/1473325015603479

Smeeton, J. (2018) "A Murky Business': A phenomenological ontology of risk in child protection social work in the UK. Qualitative Social Work. 0(0) 1-17 https://doi. org/10.1177/1473325018815732 <https://doi.org/10.1177\%2F1473325018815732>

Smith, N.H. (2002) Charles Taylor: Meanings, Morality and Modernity, Cambridge: Polity Press

Stanford, S.N. (2011) Constructing moral responses to risk: A framework for hopeful social work practice. British Journal of Social Work, 41, 1514-1531

Stang, E. (2018) Ethical decision-making in internet research: Investigating protect groups against Child Welfare Services on Facebook. in Qualitative Social Work. O(0) 1-17 DOI: $10.1177 / 1473325018796120$

Star, The (24.9.10) available at http://www.thestar.co.uk/what-s-on/out-about/case-closedtwice-by-social-services-before-alex-s-death-1-2964612 accessed 28.9.15.

Taylor, C. (1989) Source of the Self: The making of the modern identity. Cambridge, MA: Harvard University Press

Taylor, C. (1991) The Ethics of Authenticity. Cambridge, MA: Harvard University Press

Turnell, A. and Edwards, S. (1999) Signs of Safety: A solution and safety oriented approach to child protection casework. New York: Norton

Ward, J. \& Smeeton, J. (2017) The end of non-consensual adoption: promoting the well-being of children in care. Practice:, 29, 1, 55-73 https://doi.org/10.1080/09503153.2016.1164131

Webb, S.A. (2006) Social Work in a Risk Society: social and political perspectives. London: Palgrave Macmillan 